Opinion

\title{
The Invisible Handicaps of O.R.L. Detroit
}

\author{
Lucio Maci*
}

ORL Centre Medico-Legal I.N.A.I.L. Brindisi and Lecce, Italy

*Corresponding author: Lucio Maci, ORL Centre Medico-Legal I.N.A.I.L. Brindisi and Lecce, Italy.
Received Date: March 29, 2019

Published Date: April 25, 2019

\section{The Theoretical Framework and the Main Reference Concepts}

The word handicap comes from the English word "hand in cap", which means "hand in hat". In a bartering of goods between two people, it was necessary to restore an equality of value between what one gave and what one received: thus, the one who received an object of a higher value had to put in a hat a sum of money to restore equity.

According to the Declaration of the Rights of Persons with Disabilities, proclaimed by the General Assembly of the United Nations on 9 December 1975, any person who is unable to provide all or part of the necessities of life a normal individual or social life, because of a disability, congenital or not, of his physical or mental abilities.

The British Philip Wood introduced from 1980 a critical conceptual clarification in the definition of disability.

\section{It Defines Disability as the Consequence of Diseases on the Person, Analyzing them in Three Ways}

* Impairment, corresponding to the alteration of a psychological, physiological or anatomical structure or function;

* Disability, which is a partial or total reduction in the ability to perform an activity normally;

* The disadvantage, consequence of the deficiency or the incapacity on the conditions of social insertion, school or professional. The disadvantage is the result of the interaction between the person with a disability or disability and the environment. Its importance is closely linked to the quality of the environment, which can either minimize it or amplify it.

In case of disability, wetalkaboutactivity limitation. Participation refers to the involvement of a person in a real-life situation; in the case of disability, we talk about restriction of participation. The ICIDH (International Classification of Disabilities), developed at the initiative of the World Health Organization, focuses on the positive side of the individual expressed in terms of functioning, the negative side being referred to as the handicap. Any worker struggling with the consequences of occupational deafness should ideally benefit from adequate assessment, workplace adaptation, and social and professional support and rehabilitation services in order to respond to their needs. health, well-being and safety needs. This care should naturally and necessarily exceed the only principles of the logic of compensation.

The I.N.A.I.L. (Italian National Institute for the Insurance of Occupational Diseases and Work Accidents) has renewed the entire model of the old insurance system by "taking care" of the worker through a system that includes the coordination and integration of all types of services, implementing an integrated and comprehensive protection system whose objectives are optimize the privileged protection of the injured worker and / or an occupational disease; provide a comprehensive service that integrates care, assessment, compensation and rehabilitation in a unified and repeated manner; make the person disabled with their family, society and productive activity.

\section{Presentation of the Study Object and the Problematic}

The modest and certainly insufficient objective of this work is to support the need to help workers with occupational deafness, taste disorders and quantitative and / or qualitative impairments of olfaction not only through fair economic compensation due to hearing loss, but also with the help of technical support and equipment designed by modern technology. Above all, it is necessary to raise awareness of this problem, which requires a global awareness.

Disturbances of taste are considered today as disfunctions of secondary interest. Perhaps it is necessary to impute the reason to philosophers who, like Kant, established a hierarchy of the senses and relegated taste and olfaction to the rank of primitive animal senses, less noble than sight and hearing, which characterize man. refined. 
Disorders of taste, alone or in association with dyssomnia, are particularly disabling symptoms because of the profound repercussions on the personal and relational life of the affected subject. They can have serious consequences inherent in the inability to recognize possible harmful substances. It also leads to gradual changes in dietary attitudes with possible onset or aggravation of nutritional problems. Finally, there is the increase in stress and the possibility of anorexia and depression.

Although olfactory perception is limited in humans compared to animals, olfaction is fundamental in everyday life. It is useful in the perception of odors in combination with taste, in social life (food, perfumes etc.) and in the perception of danger signals (gas, burning smell). It's easy to imagine the feeling of "isolation" and the impact on the quality of life, especially in everyday activities, of an anomic subject.

The olfaction represents an important and essential vehicle of relationship with our fellow beings and with the surrounding environment. Indeed, it is a means of communication, identification, pleasure, gene, survival, seduction and orientation. Olfaction is often associated with taste by a parallel process of integration. It is therefore a sensory organ that is particularly useful and complex. Its quantitative and/or qualitative alterations, often underestimated or diagnosed with delay, constitute a significant, often irreversible, loss of the psycho-physical integrity of the individual.

Occupational deafness among workers is of considerable importance because of the costs associated with rehabilitation and social reintegration. Historically, many economic resources have been devoted to the prevention and compensation of hearing impairments.

\section{Investigative Methods Mobilized}

The study is based on the personal experience acquired over more than ten years in the I.N.A.I.L. The collection of the anamnesis data was very rigorous, an exact diagnostic orientation often arising from a well conducted anamnesis. This included information about the pattern of occurrence, the characteristics, the duration of the various symptoms reported by the patient, addictive behaviors, lifestyle, the possible alteration of taste, the presence of others. systemic pathologies or ENT strains, traumatic history and medication. The management of a patient with a taste disorder is still very complex, particularly in the aftermath of head trauma [1] where this symptom is neglected by the person himself, who is more concerned about vital issues and who is often convinced of the temporary nature of the phenomenon. The long-time interval before awareness of the disease prevents rapid treatment.

For the doctor, the most urgent is the anamnesis. It is necessary to speak with the patient not only of the trauma but also of the problems met with the hospital, the return to the home, to look for a possible loss of weight, changes of way of life, disorders of the mood. Once the symptom has been identified, the disease must be confirmed clinically and paraclinically [2-7].
Unfortunately, the objective methods are still largely in the process of experimentation and have not yet enough validity, reproducibility, sensitivity, specificity, reliability. They are not yet standardized, are too expensive and are still underdeveloped. The occupational physician must be aware of these problems in order to be able to intervene in time if the situation requires it. It is reasonable to hope that this long journey will be handled by specialists who will work in synergy.

\section{The Main Results Based on a Collection of Empirical Data}

There are two constant elements: shame and underestimation of the problem. The long-time interval before awareness of the disease prevents rapid treatment. Especially in the aftermath of head trauma these symptoms are neglected by the person himself, who is more concerned about vital issues and who is often convinced of the temporary nature of the phenomenon. The worker affected by these illnesses does not find comfort very often in the family, in the workplace, or in the health care system.

Sometimes we have the impression that we also need to inform the family, the society and the distraction of certain doctors. Above all, the invisibility of these problems must be demonstrated without hesitation, confrontation and acceptance. This implies the coordinated and combined application of measures in the medical, social, psychic, technical and pedagogical fields, which may help to postpone the patient in the place that best suits him in society and / or to maintain his place.

\section{Acknowledgements}

\section{None}

\section{Conflict of interest}

No conflict of interest

\section{References}

1. Schechter PJ, Henkin RI (1974) Abnormalities of taste and smell after head trauma. J Neurol Neurosurg Psychiatry 37 (7): 802-810.

2. Maci L (2008) Aspetti medico-legali del danno olfattivo. Argomenti di Otorinolaringoiatria Moderna 8(15): 8-21.

3. Uziel A, Guerrier Y (1975) L'exploration fonctionnelle de l'olfaction et son rôle dans le diagnostic des troubles de l'odorat. Ann Oto-Laryng 9: 475-490.

4. Maci L (2006) Di Pierri C-La surdité professionnelle en France et en Italie.Prat Organ Soins 37(3): 227-233.

5. Maci L (1999) Sull'accertamento della pretestazione di lesività in audiologia a fini medico-legali. Riv Infortuni Malattie Professionali 4-5: 751.

6. Maci L, De belvis AG, Assennato AC, Pagano V, Tavolaro M (2017) Bilateral hearing asymmetry and lateral differences in susceptibility to noise damage. Pulsus J Surgical Res 1: 15-16.

7. ALAJMO E (1988) Otorinolaringoiatria, Ed. Piccin, padova university, Italy. 